Огляди літератури, оригінальні дослідження, погляд на проблему, випадок з практики, короткі повідомлення УДК 616.24-002.2-007.272:616.24-616.155.194:615.356]-036-08

DOI 10.11603/1811-2471.2020.v.i2.11323

\title{
ЕФЕКТИВНІСТЬ ЗАСТОСУВАННЯ ВІТАМІНОТЕРАПІЇ Й АМІНОКИСЛОТНОГО ПРЕПАРАТУ В КОМПЛЕКСІ ЛІКУВАННЯ ХРОНІЧНОГО ОБСТРУКТИВНОГО ЗАХВОРЮВАННЯ ЛЕГЕНЬ ІЗ СУПУТНЬОЮ АНЕМІЄЮ ХРОНІЧНИХ ЗАХВОРЮВАНЬ У ПАЦІЄНТІВ, ЩО ПЕРЕНЕСЛИ ТУБЕРКУЛЬОЗ ЛЕГЕНЬ
}

\author{
○Н. В. Жованик', М. І. Товт-Коршинська², М. В. Ростока-Резнікова² \\ ${ }^{1} \mathrm{KHП} \mathrm{«Закарпатська} \mathrm{обласна} \mathrm{клінічна} \mathrm{лікарня»} \mathrm{імені} \mathrm{А.} \mathrm{Новака} \mathrm{Закарпатської} \mathrm{обласної} \mathrm{ради}$ \\ ${ }^{2}$ ДВНЗ «Ужгородський національний університет»
}

\begin{abstract}
РЕЗЮМЕ. Мета дослідження - вивчити можливості застосування вітамінотерапії (ВТ) і амінокислотного препарату в комплексі лікування хронічного обструктивного захворювання легень (ХОЗЛ) із супутньою анемією хронічних захворювань (АХЗ) у пацієнтів, що перенесли туберкульоз легень (ТБЛ).

Матеріал і методи. Обстежено 95 пацієнтів із ХОЗЛ і перенесеним ТБЛ та АХЗ згідно з діючими протоколами із дослідженням показників обміну заліза, а також тривожності та депресії, і додатковим призначенням вітамінів групи В з або без адеметіоніну до стандартного лікування ХОЗЛ.

Результати. Додаткове призначення ВТ з або без амінокислотного препарату (адеметіоніну) до стандартної фармакотерапії ХОЗЛ у поєднанні з перенесеним ТБЛ і АХЗ дозволило досягти достовірної позитивної динаміки не тільки клініко-функціонального стану, а й показників червоної крові, а також зниження інтенсивності запального процесу та індексу депресії, більше виражене в групі, в якій призначали і вітаміни, і амінокислотний препарат. Застосування тільки стандартної фармакотерапії дозволило досягти достовірного покращення клініко-функціональних показників без істотних змін показників червоної крові, системного запалення та психологічного стану.

Висновки. Пацієнтам із ХОЗЛ і супутньою АХЗ, що перенесли ТБЛ, додатково до стандартної терапії доцільно призначати вітамінотерапію і амінокислотний препарат для корекції показників червоної крові, нормалізації показників системного запалення та індексу депресії.
\end{abstract}

КЛючОВІ СлОВА:хронічне обструктивне захворювання легень; залишкові зміни після туберкульозу легень; анемія хронічних захворювань; вітамінотерапія; амінокислотний препарат.

Вступ. Хронічне обструктивне захворювання легень (ХОЗЛ) є однією із найпоширеніших хвороб органів дихання і важливою причиною інвалідизації та передчасної смерті населення [1]. Важливим фактором обтяження перебігу ХОЗЛ $\epsilon$ перенесений ТБЛ, після якого залишаються стійкі довічні зміни - залишкові зміни після перенесеного ТБЛ (ЗЗТБ). Пацієнти з ХОЗЛ і ЗЗТБ характеризуються тяжким перебігом і нестійким ефектом лікування ХОЗЛ навіть у віддаленому періоді після вилікуваного ТБЛ унаслідок активації системного запалення та зниження місцевого імунітету слизової оболонки дихальних шляхів [2], що може підвищувати схильність до подальших тяжких загострень ХОЗЛ.

Анемія діагностується у 16-30\% пацієнтів із ХОЗЛ і 16-94 \% хворих на ТБЛ, що значно більше, ніж у загальній популяції. Згідно з даними літератури, у пацієнтів із ХОЗЛ переважно діагностуються ЗДС, тоді як за умов ТБЛ - АХЗ $[3,4]$.

Дослідження останніх років показали, що зниження рівня гемоглобіну $\epsilon$ незалежним чинником, який підвищує ймовірність госпіталізації 3 приводу загострення ХОЗЛ протягом наступного року, особливо за умов легеневої гіпертензії. Також виявили зв'язок анемії з важливими маркерами запалення [5]. Разом із тим, прицільна діагностика та корекція анемії під час вибору тактики ведення ХОЗЛ, як правило, не проводиться.
Відомо, що показники психоемоційного реагування, зокрема, підвищена тривожність і схильність до депресії, $\epsilon$ важливими факторами, що впливають на клініко-функціональний стан паці$\epsilon н т і в$ як із ХОЗЛ, так і з анемією [6], проте у пацієнтів із ХОЗЛ і ЗЗТБ тривожність та депресія практично не вивчалися.

Наше попереднє дослідження показало, що в більшості пацієнтів із ХОЗЛ і ЗЗТБ виявлялася супутня АХ3. При цьому за умов AX3, порівняно з ії відсутністю, спостерігалися погіршення клінічного перебігу ХОЗЛ і показників функції зовнішнього дихання, більш часті загострення та госпіталізації, посилення бронхіальної обструкції та системного запалення. Крім того, серед пацієнтів із ХОЗЛ і ЗЗТБ у поєднанні з АХЗ, порівняно з групою ХОЗЛ і З3ТБ без АХЗ, виявлено достовірно вищий рівень особистісної тривожності і підвищений індекс депресії (ІД) [7].

Згідно з літературними даними, серед відносно безпечних та ефективних засобів для профілактики і лікування тривожно-депресивних тенденцій, отримано клінічний ефект після застосування комплексу вітамінів групи В [8], а також адеметіоніну [9], проте їх застосування для корекції показників психоемоційного реагування потребує подальших досліджень. Окремі дослідники вказують на обернену кореляцію рівнів вітамінів 
Огляди літератури, оригінальні дослідження, погляд на проблему, випадок з практики, короткі повідомлення групи В і маркерів запалення [10], проте їх ефекти за умов хронічного запалення і супутньої АХЗ вивчені не достатньо, а дослідження у пацієнтів із ХОЗЛ і ЗЗТБ у поєднанні з АХЗ не проводилися.

Мета - вивчити ефективність застосування вітамінотерапії і амінокислотного препарату в комплексі лікування хронічного обструктивного захворювання легень із супутньою анемією хронічних захворювань у пацієнтів, що перенесли туберкульоз легень.

Матеріал і методи дослідження. Обстежено 95 хворих, госпіталізованих із діагнозом загострення ХОЗЛ II-ІІІ ступеня тяжкості обмеження повітряного потоку (бронхіальної обструкції), що належали до груп B, C, D, на базі пульмонологічного відділення КНП «Закарпатська обласна клінічна лікарня імені А. Новака» ЗОР (м. Ужгород).

Обстеження і лікування пацієнтів проводили згідно з відповідними клінічними протоколами $[11,12]$ із врахуванням міжнародних рекомендацій GOLD-2019. Симптоми ХОЗЛ оцінювали за допомогою стандартних опитувальників (модифікована шкала задишки Британської медичної дослідницької ради - the Modified British Medical Research Council, mMRC та тесту оцінки ХОЗЛ COPD Assesment Test, CAT).

Проводили визначення функції зовнішнього дихання, рентгенографію органів грудної клітки, загальний аналіз крові (ЗАК), електрокардіографію, ехокардіографію. Усім хворим проведено визначення показників сироваткового заліза (Fe), загальної залізозв'язувальної здатності сироватки крові (333С), відсотка насичення трансферину залізом (ВНТЗ), трансферину (Тр), феритину (Фн), а також розчинного рецептора трансферину із обчисленням співвідношення розчинного рецептора трансферину до логарифма феритину для диференційної діагностики АХЗ (зниження до менше 1) і ЗДА (підвищення до понад 2) із наступною консультацією гематолога. Крім того, проведено визначення наступних показників системного запалення: С-реактивного протеїну (СРП) і компонента системи комплементу С3, глобулінів. Визначали також ІД за допомогою Beck Depression Inventory [13], Beck Depression Inventory [13].

До включення в дослідження пацієнти застосовували інгалятор тіотропію бромід 18 мкг у капсулах з доставковим пристроєм «Handy Haler» та стандартну терапію загострення ХОЗЛ: бронхолітичну (метилксантини - еуфілін 2,4 \% розчин - по 5-10 мл внутрішньовенно у 10-20 мл ізотонічного розчину хлориду натрію, теотард 200 мкг 2 рази/ день) і муколітичну терапію (бромгексин по 8-16 мг 3 рази/день або амброксол по 30 мг 3 рази/день), а також дексаметазон внутрішньовенно протягом 7 днів.

Для диференційного лікування пацієнтів із ХОЗЛ і З3ТБ та супутньою АХ3 (n=95) було виділено 3 групи, що достовірно не відрізнялися за віком і статтю. Пацієнти групи 1 (n=33) додатково до стандартної терапії з 5-го дня лікування загострення ХОЗЛ (після усунення найгостріших явищ бронхіальної обструкції та системного запалення) приймали вітамінотерапію (ВТ) у вигляді комбінації вітамінів групи $\mathrm{B}$, а також амінокислотний препарат - 500 мг адеметіоніну по 1 таблетці 1 р/д. Пацієнтам призначали комплекс вітамінів групи В внутрішньом'язово протягом перших 5 днів (розчин для ін'єкцій у вигляді ампул по 2 мл, 1 мл містить піридоксину гідрохлориду 50 мг, тіаміну гідрохлориду 50 мг, ціанокобаламіну 0,5 мг) із переходом на пероральний прийом по 1 таблетці (піридоксину гідрохлориду 100 мг, бенфотіаміну 100 мг) 1 раз на добу. Загальний курс комплексного лікування склав 30 днів. Пацієнти групи 2 ( $\mathrm{n=32})$ додатково приймали тільки ВТ (режим дозування такий же, як у групі 1). Пацієнти групи 3 (n=30) приймали тільки стандартну терапію ХОЗЛ.

Статистичну обробку результатів дослідження проводили за допомогою пакета прикладних програм Statistica 10.0 (StatSoft Inc., USA).

Результати й обговорення. Динаміка окремих показників клініко-функціонального стану пацієнтів наведена в таблиці 1.

Таблиця 1. Динаміка окремих показників клініко-функціонального стану в процесі лікування хронічного обструктивного захворювання легень у поєднанні з анемією хронічних захворювань у пацієнтів, що перенесли

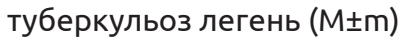

\begin{tabular}{|c|c|c|c|c|c|c|}
\hline \multirow{2}{*}{ Показник } & \multicolumn{2}{|c|}{$\begin{array}{c}\text { Група } 1 \text { (n=33), вітамінотерапія } \\
\text { + амінокислотний препарат }\end{array}$} & \multicolumn{2}{|c|}{$\begin{array}{l}\text { Група } 2 \text { (n=32), } \\
\text { вітамінотерапія }\end{array}$} & \multicolumn{2}{|c|}{$\begin{array}{c}\text { Група } 3 \text { ( } \mathrm{n=30),} \\
\text { тільки стандартна терапія }\end{array}$} \\
\hline & до лікування & після лікування & до лікування & $\begin{array}{c}\text { після } \\
\text { лікування }\end{array}$ & до лікування & $\begin{array}{c}\text { після } \\
\text { лікування }\end{array}$ \\
\hline МДР, балів & $1,74 \pm 0,41$ & $1,12 \pm 0,16^{*}$ & $1,82 \pm 0,38$ & $1,22 \pm 0,11$ * & $1,88 \pm 0,53$ & $1,17 \pm 0,14^{*}$ \\
\hline TOX, балів & $17,9 \pm 0,42$ & $12,78 \pm 0,83^{*}$ & $18,84 \pm 0,76$ & $13,11 \pm 0,75^{*}$ & $17,92 \pm 0,53$ & $12,73 \pm 0,72 *$ \\
\hline $\mathrm{OФB}_{1}, \%$ & $48,56 \pm 2,21$ & $63,35 \pm 2,44^{*}$ & $49,35 \pm 2,68$ & $59,52 \pm 3,67 *$ & $49,03 \pm 2,6$ & $58,72 \pm 2,97^{*}$ \\
\hline
\end{tabular}

Примітки: 1. * - р<0,05 порівняно з початком лікування;

2. + - p<0,05 порівняно з групою, що приймала тільки вітамінотерапію;

3. \# - p<0,05 порівняно з групою, що приймала тільки стандартну терапію. 
Огляди літератури, оригінальні дослідження, погляд на проблему, випадок з практики, короткі повідомлення

У всіх клінічних групах виявлено певну динаміку як показників клінічного перебігу (зменшення задишки за МДР та інтенсивності основних симптомів за ТОX), так і функції зовнішнього дихання (зростання ОФВ $)$ у процесі лікування, без суттєвої різниці серед пацієнтів, що додатково приймали адеметіонін і / або вітаміни групи В, порівняно з групою, в якій призначали тільки стандартну фармакотерапію ХОЗЛ.

Під час аналізу динаміки рівня гемоглобіну і еритроцитів, а також окремих показників системного запалення, було виявлено таке (табл. 2).

Таблиця 2. Динаміка окремих результатів лабораторних методів дослідження в процесі лікування хронічного обструктивного захворювання легень у поєднанні з анемією хронічних захворювань у пацієнтів, що перенесли туберкульоз легень $(\mathrm{M} \pm \mathrm{m})$

\begin{tabular}{|c|c|c|c|c|c|c|}
\hline \multirow{2}{*}{ Показник } & \multicolumn{2}{|c|}{$\begin{array}{l}\text { Група } 1 \text { (n=33), вітамінотерапія } \\
\text { + амінокислотний препарат }\end{array}$} & \multicolumn{2}{|c|}{ 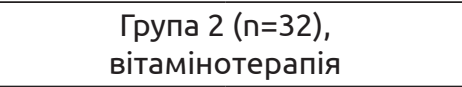 } & \multicolumn{2}{|c|}{$\begin{array}{c}\text { Група } 3 \text { ( } \mathrm{n=30),} \\
\text { тільки стандартна терапія }\end{array}$} \\
\hline & до лікування & $\begin{array}{c}\text { після } \\
\text { лікування }\end{array}$ & до лікування & $\begin{array}{c}\text { після } \\
\text { лікування }\end{array}$ & до лікування & $\begin{array}{c}\text { після } \\
\text { лікування }\end{array}$ \\
\hline $\mathrm{Hb}, г / л$ & $112,36 \pm 4,05$ & $128,21 \pm 3,17 * \#$ & $113,41 \pm 3,56$ & $125,57 \pm 3,85^{*} \#$ & $111,71 \pm 3,52$ & $116,15 \pm 3,85$ \\
\hline $\mathrm{RBC}$, ×109/л. & $3,21 \pm 0,24$ & $4,16 \pm 0,35 * \#$ & $3,48 \pm 0,15$ & $4,18 \pm 0,45^{*} \#$ & $3,32 \pm 0,28$ & $3,45 \pm 0,22$ \\
\hline ШОЕ, мм/год & $19,14 \pm 4,23$ & $12,02 \pm 3,06 *$ & $18,71 \pm 3,52$ & $11,74 \pm 2,08 *$ & $18,33 \pm 2,76$ & $11,95 \pm 2,88$ * \\
\hline СРП, мг/л & $11,86 \pm 0,52$ & $6,48 \pm 0,34 *+\#$ & $12,02 \pm 0,46$ & $8,32 \pm 0,44 * \#$ & $11,74 \pm 0,83$ & $10,32 \pm 0,93$ \\
\hline $\mathrm{C}_{3}$ & $2,05 \pm 0,02$ & $1,78 \pm 0,03 * \#$ & $2,1 \pm 0,05$ & $1,86 \pm 0,04 * \#$ & $2,06 \pm 0,07$ & $1,98 \pm 0,03$ \\
\hline
\end{tabular}

Примітки: 1. * - p<0,05 порівняно з початком лікування;

2. + - p<0,05 порівняно з групою, що приймала тільки вітамінотерапію:

3. \# - p<0,05 порівняно з групою, що приймала тільки стандартну терапію.

У групах пацієнтів, що додатково приймали ВТ, з або без амінокислотного препарату, після лікування виявлено достовірне зростання рівнів гемоглобіну і еритроцитів до майже нормальних величин, чого не спостерігалося у пацієнтів, що приймали тільки стандартну фармакотерапію ХОЗЛ, у яких зміни зазначених показників червоної крові були мінімальними. Істотної різниці показників гемоглобіну і еритроцитів у підгрупах, що додатково приймали тільки вітаміни групи В або комбінацію цих вітамінів із амінокислотним препаратом, не виявлено.

Після лікування виявлено достовірне зниження показника ШОЕ в усіх клінічних групах без суттєвої різниці між ними. Разом із тим, у підгрупах, що додатково приймали ВТ з або без амінокислотного препарату, спостерігалося достовірне зниження рівнів СРП і С , що свідчило про зменшення інтенсивності системного запалення, тоді як у групі пацієнтів, що приймали тільки стандартну терапію, відмічено лише тенденцію до їх зниження.

У групі пацієнтів, яким призначали і вітаміни групи В, і амінокислотний препарат, динаміка СРП була найбільш вираженою, і його рівень після лікування виявився достовірно нижчим, порівняно $з$ групами хворих, що приймали тільки ВТ або тільки стандартну терапію ХОЗЛ. Імовірно, істотне зниження інтенсивності хронічного запального процесу, як важливого чинника $A X 3$, у пацієнтів перших двох груп сприяло кращій компенсації рівнів гемоглобіну і еритроцитів у процесі лікування.

Аналогічна тенденція спостерігалася під час аналізу динаміки індексу депресії в процесі ліку- вання: виявлено достовірне його зниження у групах, що додатково приймали ВТ і амінокислотний препарат $(19,06 \pm 0,53$ до лікування і 8,77 $\pm 0,23$ після лікування, $p<0,05)$ або тільки ВТ $(19,25 \pm 0,23$ i

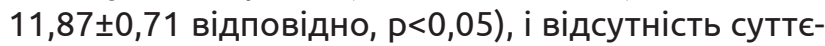
вої динаміки у групі хворих, що приймали тільки

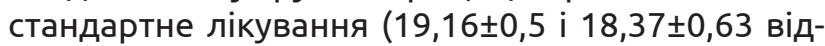
повідно, р>0,05). При цьому нормалізація ІД спостерігалася тільки у групі пацієнтів, яким додатково призначалася комбінація вітамінів групи В і адеметіоніну.

Висновки. 1. У пацієнтів із ХОЗЛ і ЗЗТБ та супутньою АХЗ додаткове призначення вітамінотерапії з або без амінокислотного препарату сприяло істотному покращенню не тільки клініко-функціонального стану, а й показників гемоглобіну та еритроцитів, зниженню інтенсивності запалення та ІД. За умов стандартного лікування ХОЗЛ у хворих, які перенесли ТБЛ та мали супутню АХЗ, зміни показників червоної крові, запалення та рівня депресії були не вірогідними.

2. Оптимальні результати, особливо для корекції системного запалення і психоемоційного стану, отримані при поєднаному застосуванні вітамінотерапії та амінокислотного препарату додатково до стандартного лікування ХОЗЛ у паці$\epsilon$ нтів із супутньою АХ3, що перенесли ТБЛ.

3. Пацієнтам із ХОЗЛ і перенесеним ТБЛ та супутньою АХ3, особливо за умов підвищеного рівня депресивних тенденцій, доцільно призначати комбінацію вітамінів групи В у поєднанні з амінокислотним препаратом адеметіоніном додатково до стандартної фармакотерапії ХОЗЛ. 


\section{ЛІТЕРАТУРА}

1. Адаптована клінічна настанова: хронічне обструктивне захворювання легень (частина 1) / Ю.І.Фещенко, В. К. Гаврисюк, О. Я. Дзюблик [та ін.] // Український пульмонологічний журнал. - 2019. - Т. 2. - С. 5-18.

2. Zakaria M. W. Chronic obstructive pulmonary disease in treated pulmonary tuberculous patients / M. W. Zakaria, H. A. Moussa // Egyptian Journal of Bronchology. - 2015. - Vol. 9. - P.10-13.

3. Tuberculosis-associated anemia is linked to a distinct inflammatory profile that persists after initiation of antitubercular therapy / L. Gil-Santana, L. A. B Cruz, M. B. Arriaga [et al.] // Sci. Rep. - 2019. - Vol. 9. - P. 1381. DOI: $10.1038 /$ s41598-018-37860-5

4. Impact of COPD and anemia on motor and cognitive performance in the general older population: results from the English longitudinal study of ageing / I. Padberg, A. Schneider, J. Lee Rohmann [et al.] // Respir. Res. 2020. - Vol. 21. - P. 40. DOI: 10.1186/s12931-020-1305-6

5. The influence of anemia on one-year exacerbation rate of patients with COPD-PH / W. Xiong, M. Xu, B. Pudasaini [et al.] // BMC Pulmonary Medicine. -2018. - Vol. 18. P. 143. DOI: 10.1186/s12890-018-0693-6

6. Yohannes A. Depression and anxiety in patients with COPD / A. M. Yohannes, G. S. Alexopoulos // European respiratory review: an official journal of the European Respiratory Society. - 2014. - Vol. 23. - P. 345-349. DOI: $10.1183 / 09059180.00007813$

7. Жованик Н. В. Особливості діагностики та лікування хронічного обструктивного захворювання легень із супутньою анемією хронічних захворювань у осіб, що перенесли туберкульоз легень / Н. В. Жованик,
М. І. Товт-Коршинська, М. В. Ростока-Резнікова // Eurasisn Scientific Congress. Abstracts of the 3rd International Scientific and Practical Conference. Barca Academy Publishing. - Barcelona, Spain. - 2020. - P. 79-85.

8. Mikkelsen K. The effects of vitamin B in depression / K. Mikkelsen, L. Stojanovska, V. Apostolopoulos // Current Medicinal Chemistry. - 2016. - Vol. 23. DOI: 10.21 74/0929867323666160920110810.

9. Sadenosyl methionine (SAMe) for depression in adults / I. Galizia, L. Oldani, K. Macritchie [et al.] // Cochrane Database of Systematic Reviews. - 2014. - Vol. 9. CD011286. DOI: 10.1002/14651858.CD011286

10. B vitamin status and inflammatory markers / A. R. Folsom, M. Desvarieux, F. J. Nieto [et al.] // Atherosclerosis. - 2003. - Vol. 169 (1). - P. 169-174.

11. Про затвердження уніфікованого клінічного протоколу первинної, вторинної (спеціалізованої) та третинної (високоспеціалізованої) медичної допомоги та медичної реабілітації хронічного обструктивного захворювання легень : наказ МОЗ України № 555 від 27.06.2013 р. [Текст] / Міністерство охорони здоров'я України. - Офіц. вид. - Київ, 2013. - 146 с.

12. Уніфікований клінічний протокол первинної, вторинної (спеціалізованої) медичної допомоги. Залізодефіцитна анемія : наказ МОЗ України № 709 від 02 листопада 2015 р. [Текст] / Міністерство охорони здоров'я України. - Офіц. вид. - Київ, 2015. - 49 с.

13. Beck Depression Inventory-II [online]. - Access mode : https://www.kdheks.gov/c-f/integration_toolkits/ Beck_Depression_Inventory_II.pdf

\section{REFERENCES}

1. Feshhenko, Yu.I., Gavrysyuk, V.K., Dzyublyk, O.Ya., Mostovoy, Yu.M., Pertseva, T.O., Polyanska, M.O., Yachnyk, A.I., \& Yashyna, L.O. (2019). Adaptovana klinichna nastanova: khronichne obstruktyvne zakhvoriuvannia lehen (chastyna 1) [Adapted clinical guidelines: chronic obstructive pulmonary disease (part 1)]. Ukrainskyi pulmonolohichnyi zhurnal - Ukrainian Pulmonology Journal, 2, 5-18 [in Ukrainian].

2. Zakaria, M.W., \& Moussa, H.A. (2015). Chronic obstructive pulmonary disease in treated pulmonary tuberculous patients. Egyptian Journal of Bronchology, 9, 10-13.

3. Gil-Santana, L., Cruz, L.A.B., Arriaga, M.B., Miranda, F.C., Fukutani, K.F., Silveira-Mattos, P.S., ..., \& Andrade B.B. (2019) Tuberculosis-associated anemia is linked to a distinct inflammatory profile that persists after initiation of antitubercular therapy. Sci. Rep., 9, 1381. DOI: 10.1038/s41598018-37860-5.

4. Padberg, I., Schneider, A., Lee Rohmann, J., Kelley, S.W., Grittner, U., \& Siegerink, B. (2020). Impact of COPD and anemia on motor and cognitive performance in the general older population: results from the English longitudinal study of ageing. Respir. Res., 21, 40. DOI: 10.1186/ s12931-020-1305-6

5. Xiong, W., Xu, M., Pudasaini, B., Guo, X., \& Liu, J. (2018) The influence of anemia on one-year exacerbation rate of patients with COPD-PH. BMC Pulmonary Medicine, 18, 143. DOI: $10.1186 / \mathrm{s} 12890-018-0693-6$

6. Yohannes, A. \& Alexopoulos, G. (2014) Depression and anxiety in patients with COPD. European Respiratory Review: An Official Journal of the European Respiratory Society, 23, 345-349. DOI: 10.1183/09059180.00007813.

7. Zhovanyk, N.V., Tovt-Korshynska, M.I., \& RostokaReznikova, M.V. (2020). Osoblyvosti diahnostyky ta likuvannia khronichnoho obstruktyvnoho zakhvoriuvannia lehen iz suputnoiu anemiieiu khronichnykh zakhvoriuvan u osib, shcho perenesly tuberkuloz lehen [Features of diagnosis and treatment of chronic obstructive pulmonary disease with concomitant anemia of chronic diseases in persons who have suffered from pulmonary tuberculosis]. Eurasisn Scientific Congress. Abstracts of the 3rd International Scientific and Practical Conference. Barca Academy Publishing. Barcelona. Spain [in Ukrainian].

8. Mikkelsen, K., Stojanovska, L., \& Apostolopoulos, V. (2016). The effects of vitamin B in depression. Current Medicinal Chemistry, 23. DOI: 10.2174/092986732366616092 0110810.

9. Galizia, I., Oldani, L., Macritchie, K., Amari, E., Dougall, D., Jones, T.N. ..., \& Young, A.H. (2014). Sadenosyl methionine (SAMe) for depression in adults. Cochrane Database of 
Огляди літератури, оригінальні дослідження, погляд на проблему, випадок з практики, короткі повідомлення Systematic Reviews, 9, CD011286. DOI: 10.1002/14651858. CD011286.

10. Folsom, A.R., Desvarieux, M., Nieto, F.J., Boland, L.L., Ballantyne, C.M., \& Chambless, L.E. (2003). B vitamin status and inflammatory markers. Atherosclerosis, 169 (1), 169-174.

11. (2013). Pro zatverdzhennia unifikovanoho klinichnoho protokolu pervynnoi, vtorynnoi (spetsializovanoi) ta tretynnoi (vysokospetsializovanoi) medychnoi dopomohy ta medychnoi reabilitatsii khronichnoho obstruktyvnoho zakhoriuvannia lehen: nakazu MOZ Ukrainy № 555 vid 27.06.2013 r. [On approval of the unified clinical protocol of primary, secondary (specialized) and tertiary (highly specialized) medical care and medical rehabilitation of chronic obstructive pulmonary disease: order of the Mi-

nistry of Health of Ukraine No. 555 of 27.06.2013]. Ministerstvo okhorony zdorovia Ukrainy - Ministry of Health of Ukraine [in Ukrainian].

12. (2015). Unifikovanyi klinichnyi protokol pervynnoi, vtorynnoi (spetsializovanoi) medychnoi dopomohy. Zalizodefitsytna anemiia. Nakaz MOZ Ukrainy № 709 vid 02 lystopada 2015 r. [Unified clinical protocol of primary, secondary (specialized) medical care. Iron deficiency anemia. Order of the Ministry of Health of Ukraine No. 709 of November 2, 2015]. Ministerstvo okhorony zdorovia Ukrainy - Ministry of Health of Ukraine [in Ukrainian].

13. Beck Depression Inventory-II [online resource]. Retrieved from: https://www.kdheks.gov/c-f/integration_ toolkits/Beck_Depression_Inventory_II.pdf

\title{
ЭФФЕКТИВНОСТЬ ПРИМЕНЕНИЯ ВИТАМИНОТЕРАПИИ И АМИНОКИСЛОТНОГО ПРЕПАРАТА В КОМПЛЕКСЕ ЛЕЧЕНИЯ ХРОНИЧЕСКОЙ ОБСТРУКТИВНОЙ БОЛЕЗНИ ЛЕГКИХ С СОПУТСТВУЮЩЕЙ АНЕМИЕЙ ХРОНИЧЕСКИХ ЗАБОЛЕВАНИЙ У ПАЦИЕНТОВ, ПЕРЕБОЛЕВШИХ ТУБЕРКУЛЕЗОМ ЛЕГКИХ
}

\author{
○Н. В. Жованик', М. И. Товт-Коршинская ${ }^{2}$, М. В. Ростока-Резникова ${ }^{2}$ \\ ${ }^{1}$ КНП «Закарпатская областная клиническая больница имени А. Новака» $30 С$ \\ 2"Ужгородский национальный университет»
}

РЕЗЮМЕ. Цель исследования - изучить возможности применения витаминотерапии (ВТ) и аминокислотного препарата в комплексе лечения хронического обструктивного заболевания легких (ХОЗЛ) с сопутствующей анемией хронических заболеваний (АХЗ) у пациентов, переболевших туберкулезом легких (ТБЛ).

Материал и методы. Обследовано 95 пациентов с ХОЗЛ и сопутствующей АХЗ и перенесенным ТБЛ согласно действующим протоколам с исследованием показателей обмена железа, а также тревожности и депрессии, и дополнительным назначением витаминов группы В с или без адеметионина к стандартному лечению ХОЗЛ.

Результаты. Назначение аминокислотного ВТ с или без адеметионина в дополнение к стандартной фармакотерапии ХОЗЛ с ТБЛ в анамнезе и АХЗ позволило достичь достоверной положительной динамики не только клинико-функционального состояния, но и показателей красной крови, а также снижения интенсивности воспаления и индекса депрессии, более выраженные при назначении комбинации витаминов и аминокислотного препарата. Применение только стандартной фармакотерапии позволило достичь достоверного улучшения клиникофункциональных показателей без существенных изменений показателей красной крови, системного воспаления и уровня депрессии.

Выводы. Пациентам с ХОБЛ и ТБЛ в анамнезе с сопутствующей АХЗ целесообразно назначать витаминотерапию и аминокислотный препарат дополнительно к стандартной терапии для коррекции показателей красной крови, нормализации показателей системного воспаления и индекса депрессии.

КЛюЧЕВЫЕ СЛОВА: хроническое обструктивное заболевание легких; перенесенный туберкулез легких; анемия хронических заболеваний; витаминотерапия; аминокислотный препарат.

\section{EFFICIENCY OF VITAMIN THERAPY AND AMINO ACID DRUG USE IN COMPLEX TREATMENT FOR CHRONIC OBSTRUCTIVE PULMONARY DISEASE WITH CONCOMITANT ANEMIA OF CHRONIC DISEASES IN PATIENTS WITH PULMONARY TB HISTORY}

\author{
ON. V. Zhovanyk', M. I. Tovt-Korshynska², M. V. Rostoca-Reznikova ${ }^{2}$ \\ ${ }^{1}$ Transcarpathian Regional Clinical Hospital named after A. Novak of Transcarpathian Regional Council \\ ${ }^{2}$ Uzhhorod National University
}

SUMMARY. The aim of the study - to learn the efficiency of vitamin therapy and amino acid drug use in treatment of chronic obstructive pulmonary diseases (COPD) in patients with anemia of chronic diseases (ACD) and a history of pulmonary tuberculosis (TB). 
Огляди літератури, оригінальні дослідження, погляд на проблему, випадок з практики, короткі повідомлення

Material and Methods. 95 COPD patients with ACD and a history of TB were examined according to the clinical protocols with iron metabolism study, anxiety and depression index detection, and who additionally to the standard COPD treatment received group B vitamins with or without amino acid (ademetionine) drug.

Results. In COPD patients with ACD and a history of TB a prescription of group B vitamins with or without amino acid (ademetionine) drug additionally to the standard COPD treatment lead to significant improvement not only of clinical presentation and pulmonary function tests but of red blood characteristics, decrease in inflammation intensity and depression index as well, predominantly in the group of patients who took a combination of group B vitamins and ademetionine.

Conclusions. It is advisable to prescribe vitamin therapy and amino acid drug in addition to standard therapy for the correction of red blood counts, the normalization of systemic inflammation and the depression index for patients with a history of COPD and TB.

KEY WORDS: chronic obstructive pulmonary disease; history of pulmonary tuberculosis; anemia of chronic diseases; vitamin therapy; amino acid drug.

Отримано 22.05.2020 